\title{
房屋土木工程中大体积混凝土结构的施工技术分析
}

高永仙

通号工程局集团城建工程有限公司，山西 太原 030000

[摘要] 大体积混凝土结构施工具备重要意义，但从实际施工中可以看出，该项施工极容易受到相关因素影响。文章中对大体 积混凝土结构优势及特征进行总结, 并从强化混凝土的抗拉强度、控制温度影响、抗裂功能技术的提高、开展动态监督、材 料配合比设计五方面, 论述了房屋土木工程中大体积混凝土结构施工技术内容。

[关键词]土木工程; 大体积混凝; 施工技术

DOI：10.33142/aem.v1i1.788 中图分类号：Z87 文献标识码：A

\section{Construction Technology Analysis of Mass Concrete Structure in Building Civil Engineering}

GAO Yongxian

Tonghao Engineering Bureau Group Chengjian Engineering Co., Ltd., Taiyuan, Shanxi, 030000

\begin{abstract}
The construction of mass concrete structure is of great significance, but it can be seen from the actual construction that the construction is easily affected by related factors. In this paper, the advantages and characteristics of mass concrete structure are summarized, and the construction technology of mass concrete structure in building civil engineering is discussed from five aspects: strengthening the tensile strength of concrete, controlling the influence of temperature, improving the anti-crack function technology, developing dynamic supervision and material mix proportion design.
\end{abstract}

Key words: civil engineering; mass coagulation; construction technology

引言

站在实际工程建设角度来说, 大体积混凝土属于关键原料, 尤其是在优质大体积混凝土应用上, 能够让土木工程 建设更加完善, 效果极为明显。但站在实际工作角度来说, 我国近年来大体积混凝土结构应用情况并不乐观, 裂缝现 象频繁出现, 降低了主体工程建设质量。为此, 工作人员应提升该项问题的重视程度。

\section{1 大体积混凝土结构优势及特征}

\section{1 结构优势}

随着时代的不断发展和进步, 在实际建筑设计上, 相关工作人员需要转变思想观念, 维护士建工程的全面发展。 但从土建工程实际建设情况来看, 很多遗留性问题容易被工作人员忽略。之所以会出现上述问题, 主要是由于土建工 程之中结构和材质容易出现很多缺陷, 人们需要采取针对性措施, 开展有效的弥补和完善操作。土木工程建筑中的混 凝土裂缝问题最为常见, 工作人员应在工作中深入分析裂缝出现原因, 并采取相应的补救操作, 让整体建筑结构始终 处于安全状态。

\section{2 结构特征}

大体积混凝土结构在土木建筑工程领域的应用, 想要将其作用充分发挥出来, 工作人员需要对以下几方面因素进 行考量, 如水泥材料的水化热反应, 以及混凝土自身结构缺陷等等。另外, 从实际大体积混凝土应用中也可以看出, 极容易受到相关应力条件的束缚, 从而为具体采购和工艺选择提出了更好要求。整体来看, 在实际混凝土原料组成和 设计上, 存在明显的比例要求, 当开展混凝土浇筑工作时, 大体积混凝土浇筑应尽量一次性浇筑成型, 这也是避免施 工间隙的最有效方式。当所有工作全面完成之后, 工作人员还要对具体浇筑温度和施工影响因素进行合理控制, 为大 体积混凝土提供保护 ${ }^{[1]}$ 。

\section{2 房屋土木工程中大体积混凝土结构的施工影响因素}

\section{1 混凝土收缩因素}

在混凝土制作过程中, 需要加入两成水泥, 以及来达到整体结构的硬化目的, 剩下的八成水分则是借助于蒸发过 程进入到外部环境之中。也正是由于这些多余水分的蒸发, 让内部水分蒸发现象无可避免, 混凝土体积收缩现象显得 
格外严重, 增加了裂缝问题的出现几率。另外, 倘若混凝土配置比例与相关标准要求不相符, 同时也会对混凝土收缩 产生极大影响。因此, 相关施工人员在具体施工工作开展上, 应根据实际情况, 对混凝土配置比例、组合成分等内容 进行综合考量，避免混凝土大面积收缩问题出现，这也是降低裂缝几率的重要手段之一。

\section{2 混凝土原材料应用中存在的影响因素}

该类影响因素的出现, 主要是由于混凝土材料在应用过程中具备明显的批量性特征, 相关工作人员应做好实际原 材料的篮选操作, 尽量应用质地较硬的混凝土, 通过原材料的比较分析, 获得高质量混凝土。值得注意的是, 想要实 现上述目标, 工作人员要严格遵守配料的比例配置。除此之外, 从浇筑施工操作中可以看出, 浇筑方法的合理性保持 显得尤为重要, 以一次性浇筑为主线, 决不能出现反复浇筑操作等情况。站在混凝土养护环节角度来说, 人们需要按 照相关要求对养护计划进行设定, 并与具体养护工作实际情况相结合, 按照不同阶段不同要求实施养护管理。但从混 凝土原材料选择角度来说, 经常出现一些不合格材料混入其中, 影响大体积混凝土浇筑效果。为此, 相关部门一定要 做好原材料质量检测操作 ${ }^{[2]}$ 。

\section{3 温度影响因素}

大体积混凝土温度影响因素很多, 其中, 外部因素便是其中之一, 主要指外部温度中温差因素。一般情况下, 在 具体混凝土原材料选择上, 主要涉及到的内容有水、水泥以及混合料等等, 如果将混凝土当做原材料进行应用, 需要 热水量转移和存储操作。例如, 在具体混凝土原材料之中, 会涉及到水和水泥的相互转换, 使其内部产生大量热量, 也正是由于这种热量规模的聚集, 让混凝土内部和外部温差越来越大, 进而导致混凝土表面出现裂缝现象, 不利于后 续应用工作的执行。

\section{3 房屋土木工程中大体积混凝土结构施工技术内容}

\section{1 强化混凝土的抗拉强度}

在地基变形之中, 会产生强大的拉应力, 想要避免该应力超过混凝土抗拉强度, 相关工作人员应注重对其内部抗 拉强度进行强化。在此过程中, 拉力材料选择对抗拉强度影响较为严重。为此, 相关工作人员在抗拉材料选择过程中, 应选择有机纤维、金属纤维等强度高的材料。如果是在具体房屋土木工程施工操作时, 工作人员可以在实际大体积混 凝土之中添加合适的金属纤维和有机纤维, 让混凝土抗拉结构效果得到更好展示。值得注意的是, 该项工作中的温度 应力控制显得十分重要, 实际工作中, 最为常见的温度应力控制方法有覆盖法和蓄水法, 在这两种方法的作用下, 不 仅可以降低大体积混凝土内部环境中的温度应力, 同时还能将内外温差控制在合理范围内, 降低裂缝问题的出现几率

\section{2 控制温度影响}

想要对温度影响下的大体积混凝土结构裂缝问题进行控制, 工作人员需要时刻了解混凝土内外的温度变化情况和 影响因素, 让控制方法显得更具针对性, 该项措施在大体积混凝土温度控制中极为常见, 相关工作人员要确保该项措 施的合理化应用。例如, 在强制降温操作实施上, 工作人员需要在混凝土内部预留合适的排水管, 并将冷水优先排入 到混凝土内部, 以此来降低其内部温度。另外, 在水泥替代上, 可以应用水热化较低、凝结时间较长的施工材料进行 替代, 确保大体积混凝土结构降温效果, 如大坝水泥、火山灰质硅酸盐水泥等等, 当这些材料得到充分摚动时, 能够 增加混凝土结构内部热量散发。值得注意的是, 从实际施工过程中可以看出, 混凝土浇筑温度能够得到有效控制, 但 由于自身性质影响, 在实际土木工程建设时, 应避免夏天炎热季节进行施工, 避免混凝土浇筑工作出现很多新的问题 ${ }^{[3]}$ 。

\section{3 抗裂功能技术的提高}

大体积混凝土结构施工工程量较大，倘若混凝土结构之中存在裂痕问题，会对整体施工质量产生影响从，此时， 工作人员通过多种施工技术应用, 将大体积混凝土抗裂能力提升, 降低裂缝问题的出现几率。另外, 相关工作人员在 对混凝土进行配置操作时, 应严格按照相关标准选择材料, 通过反复实践操作, 确定出最佳的科学方法, 确保混凝土 抗裂能力与实际工程要求相符。值得注意的是, 整个混凝土摚拌操作的执行, 应强化混凝土和拌合物之间的粘聚力, 避免结构不均匀现象出现。工作人员也可以在混凝土之中加入配筋材料, 为混凝土抗裂能力提升创造有利条件, 还要 做好外添加剂的添加操作, 实现对混凝土收缩能力的进一步控制, 降低裂缝问题的出现几率。 


\section{4 开展动态监督}

整个混凝土浇筑工作的开展, 相关工作人员一定要结合现场工作情况, 对实际结构塌落度等数据进行收集和整理, 开展细致性测量操作, 在得到测量结构之后, 在第一时间内上报管理人员, 为后续工作提供参考。在振捣施工操作时, 相关施工企业需要进一步强化技能培训力度, 定期开展素质教育工作, 实施有效的岗位培训制度, 确保工作人员满足 技术要求后上岗, 还要强化其工作责任意识, 将良好的施工效率呈现出来。例如, 在具体振捣施工和钢筋配比上, 需 要专业技术人员负责, 管理人员也要深入施工现场开展有效的指挥和引导操作, 以插入式工作方式为主, 让混凝土振 捣操作始终保持在完整的工作状态之中, 并将插入振捣厚度集中在 $30 \mathrm{~cm}$ 左右, 垂直深度不应超过 $60 \mathrm{~cm}$ 。更为重要的是, 振捣过量或者是少振问题应得到有效避免，这也是振捣作业合理性的基本维护手段。

\section{5 材料配合比设计}

在粗骨料选择上, 应该以连续级配操作为主线, 将砂作为施工中的细骨料进行应用。相关工作人员也可以根据实 际情况, 合理调整参合料配合比例, 让外加剂显得更具有效性。具体配合原则的制定, 应该以经济性原则为主, 以维 护工程质量为前提, 适当降低单位混凝土水泥应用数量, 让粗细骨料以及掺合料配合比例保持在最佳状态。为了实现 对大体积混凝土沁水性的有效控制, 矿渣水泥选择显得尤为重要, 相关工作人员可以根据具体施工需求, 添加适量的 减水剂, 让混凝土用水量得到合理化控制, 以此来强化施工效果。当上述工作结束之后, 工作人员可以参考具体的施 工标准和结构设计需求, 明确其具体混凝土结构设计原理。

\section{4 结束语}

综上所述, 大体积混凝土结构施工在土木工程领域之中占据重要地位, 由于一线施工技术在实施过程中, 应得到 有效监督和调配, 根据实际要求开展相应的养护和振捣操作, 将实际裂缝出现原因呈现出来。通过具体的原因分析, 工作人员可以采取针对性较强的解决措施, 获得更好的土木工程建设效果。

\section{[参考文献]}

[1]方思儒. 土木工程建筑中大体积混凝土结构的施工技术要点探析 [J].建材与装饰, 2019 (22) : 22-23.

[2]张林.房屋土木工程中大体积混凝土结构的施工技术分析 [J].住宅与房地产, 2019(18) : 170.

[3] 焦健. 土木工程建筑中大体积混凝土结构的施工技术探讨 [J]. 居业, 2019(04): 99.

作者简介: 高永仙 (1984-), 助理工程师。 